\title{
Public actions taken to address water quality and quantity issues in the northwestern USA since 2002
}

\author{
R. L. Mahler ${ }^{1} \&$ M. E. Barber ${ }^{2}$ \\ ${ }^{I}$ Soil Science Division, University of Idaho, Moscow, USA \\ ${ }^{2}$ Washington State University, Pullman, USA
}

\begin{abstract}
The purpose of this paper is to document voluntary actions the general public has taken to address water quality and quantity concerns in the northwestern USA over the last 10 years. These actions have been attributed primarily to educational outreach efforts targeted at the general public by the five land grant universities in the region. Data were collected using mail-based surveys conducted at five-year intervals in 2002, 2007 and 2012. Each survey contained between 45 and 60 questions and was mailed to 2,200 randomly chosen residents of Alaska, Idaho, Oregon and Washington. Return rates in excess of 50\% were received for each survey ensuring that the results are statistically valid. The 2002 survey results were used as base line data. More than $85 \%$ of the region's adults have made lifestyle changes to address water quantity issues. For instance, $70 \%$ have installed at least one water-saving appliance in their home, $49 \%$ report that they have reduced water use in their yards, $64 \%$ have reduced water use in their home, and $32 \%$ have reduced the amount of water used washing their cars. Conversely, only $13 \%$ have not made voluntary changes to address the amount of water used. Almost $82 \%$ of adults have acted to improve water quality. Voluntary water quality actions taken include: changed the disposal of household wastes $(60 \%)$, reduced the use of fertilizers and pesticides in yards $(46 \%)$, and changed the disposal of used motor oil $(65 \%)$. Less than $19 \%$ of adults have not voluntarily addressed water quality issues in their homes. This study demonstrates that public education used to cause positive voluntary actions is very effective and may work better than the regulatory approach in this region of the USA.
\end{abstract}

Keywords: public opinion, public actions, voluntary actions, water quality, water quantity, positive life-style change. 


\section{Introduction}

The protection of planet Earth's water resources has been a paramount environmental issue in the scientific community for over 50 years. Due to public pressure to protect surface and groundwater quality and quantity many governments have resorted to a regulatory approach to deal with these complex issues; however, this approach has not always yielded the desired outcomes. Consequently, there has been a groundswell of support for voluntary actions to protect water resources [1]. Several studies have shown that a mixed approach both regulatory and voluntary actions work best [2]. Yet others have called for the integration of voluntary, regulatory and economic strategies to protect both the quality and quantity of water resources [3]. In areas where water quantity is more limiting a hybrid conservation policy including mandatory restrictions on use, fines for overuse and pricing increases actually could be a more efficient policy rather than a total regulatory or voluntary approach [4]. No matter the type of approach taken to protect water resources success ultimately depends on the involvement of key stakeholder groups at the beginning of the protective effort [5].

Since 1987 in the USA an increased emphasis has been placed on public education as a mechanism to improve the nation's water resources through voluntary actions. This idea has been implemented by many federal agencies and through tax dollars money has been linked back to states to get the voluntary process rolling at the local levels. Within the United States Department of Agriculture (USDA) this process was developed and implemented through the National Institute of Food and Agriculture (NIFA) sub agency. USDA-NIFA has placed an emphasis on public education about both water quality and water quantity issues at the local, state, regional and national levels. To discourage states from developing their own water outreach plans since many water issues cross state line boundaries federal dollars were made available on a regional basis. To encourage this regional programming, approximately $\$ 78,000,000$ has been made available on a competitive basis over the last 12 years [6-8].

To accurately determine the effectiveness of regional programming, it is important both to establish base-line information about public perceptions and literacy, and then to measure change in public attitudes and actions over time. Furthermore, to identify the best opportunities for successful regional programming, it is imperative to understand the similarities and differences that exist among the target audiences. In the four-state (Alaska, Idaho, Oregon, Washington) Pacific Northwest Region, a survey instrument was developed to provide base-line information on public attitudes regarding water resources in 2002 from which future Extension programming outcomes can be measured (8). This initial regional survey documented public attitudes about water resources in 2002. At that time it was anticipated that follow-up water resource surveys would be conducted at 5- (2007), 10- (2012), 15- (2017), 20- (2022) and 25(2027) year intervals. The first follow-up survey was conducted in 2007 and was used to compare changes in attitudes about water resource issues since 2002 and examine geographic similarities and differences. The second follow-up five-year 
survey was completed in 2012. This paper evaluates the voluntary changes that the public has taken in their lives to address important water quality and quantity issues over the last 10 years.

\section{Methodology}

In 2011, a 60-question follow-up survey similar to the surveys conducted in 2002 and 2007 was developed to access public attitudes and actions taken to address water resource issues in the Pacific Northwest. The specific survey questions discussed in this article deal with actions that the public have voluntarily taken to address both water quality and water quantity issues in the Pacific Northwest. The survey target audience was a representative sample of the 9,000,000 adult residents of the four Pacific Northwest states (Alaska, Idaho, Oregon, Washington).

In addition, demographic information, including state of residence, community size, length of time residing in the region, gender, age, and educational level were also collected from survey respondents.

A target of 950 completed questionnaires was chosen as the survey goal to result in a sampling error of 4 to $6 \%$ [9]. The survey process was designed to receive a completed survey return rate in excess of $50 \%$. Addresses were obtained from a professional social sciences survey company (SSI, Norwich, CT). Four mailings were planned to achieve the $50 \%$ return rate [10]. The mailing strategy used was identical to that of the 2002 and 2007 samplings $[11,12]$.

Surveys were actually sent to 2,126 residents; however, 240 were returned by the post office as being undeliverable. Consequently, the actual sample population was 1,886 . The survey process was designed to receive a completed survey return rate in excess of 50\%. If more than 943 surveys were returned completed, then sampling error could be assumed to be less than $5 \%(9,10)$.

It only took three mailings were to achieve this target return rate of $50 \%$. The first mailing, which took place in May 2012, included the water issues survey form, a business reply envelope, and a cover letter that: (1) identified the survey's authors; (2) explained the purpose of the survey; (3) assured the respondent of anonymity; and (4) asked the respondents to fill out and return the survey via the business reply envelope. The second mailing occurred 5 weeks later (June 2012) and consisted of a postcard that stressed the importance of the survey and remind the respondent to fill out and return the survey sent out in the first mailing. Five weeks later (August 2012), the third mailing was sent to residents who did not respond to the first or second mailing. This mailing included a reminder letter, another copy of the water issues survey, and a business reply envelope.

Survey answers were coded and entered into Microsoft Excel. Missing data were excluded from the analysis. The data were analyzed at two levels using SAS [13]. The first level of analysis generated frequencies, while the second level evaluated the impacts of demographic factors. Significance $(\mathrm{P}<0.05)$ to demographic factors was tested using a chi-square distribution [14]. 


\section{Results and discussion}

The survey methodology used in the study was not designed to be unique, but rather to be used as a tool to ascertain useful information. The survey methodology is design to track voluntary implementation of best water management practices and to determine additional educational needs. Appropriate education programs will be developed for Pacific Northwest audiences based on this information.

The 2012 Pacific Northwest Water Issues Survey achieved a return rate of $54.1 \%$ (1,021 either fully or partially completed and returned out of 1,886$)$. The individual state responses ranged from 49.3 to $64.5 \%$ (Table 1). Fifty-five percent of the survey respondents were male. Over $38 \%$ of survey respondents lived in communities of more than 100,000 people. Conversely, $16 \%$ of respondents lived in towns with less than 7,000 people. Thirty-nine percent of respondents had lived in the Pacific Northwest all of their lives. Ninety percent of survey respondents were high school graduates. Overall, the demographics of the survey respondents (except for gender) closely reflected the actual demographics of the region. Consequently, when coupled with the low sampling error of the survey, respondents are often equated to residents in the following discussion.

Table 1: $\quad$ Pacific Northwest Water Issues Survey sample size and completion rate by state.

State $\quad$ Population Sample size Completed Return rate, \%

\begin{tabular}{lrrrr} 
Alaska & 731,000 & 227 & 112 & 49.3 \\
Idaho & $1,595,000$ & 290 & 187 & 64.5 \\
Oregon & $3,899,000$ & 540 & 270 & 50.0 \\
Washington & $6,897,000$ & 829 & 452 & 54.5 \\
Total & $13,122,000$ & 1,886 & 1,021 & 54.1 \\
\hline
\end{tabular}

Although the data is not presented in this paper, the 2002, 2007 and 2012 surveys showed that over $90 \%$ of Pacific Northwest respondents considered clean drinking water, clean rivers, and clean groundwater as high priority. In addition over two-thirds of Pacific Northwest residents indicated that water for power generation, water for agriculture, water for economic development, prevention of the loss of wetlands, prevention of salmon extinction, and watershed restoration were high priority. This general information indicates that water issues are considered high priority by residents of the region. 


\subsection{Voluntary actions to protect water quality}

Voluntary actions by Pacific Northwest residents to protect water quality improved in 2012 compared to the results of the 2002 and 2007 surveys (Tables 2 and 3). The percentage of respondents that improved home waste disposal practices, improved their use of pesticides and/or fertilizers in their yards, and safely disposed of used motor oil in 2012 was 60.2, 46.4 and 65.3\%, respectively (Table 2). These actions in 2012 were significantly higher than actions in 2002 and 2007 (Table 3). In fact only 18.6\% of residents reported in the 2012 survey that they did not take at least one voluntary action to protect water quality. This portion of survey respondents that took no action in 2012 is statistically lower than no actions reported in 2007 (26.2\%) and 2002 (45.6\%) (Table 3).

Table 2: Percentage of survey respondents who have taken a voluntary action to protect water quality based on responses to the 2002, 2007 and 2012 surveys.

\begin{tabular}{|c|c|c|c|}
\hline Action & 2002 & 2007 & 2012 \\
\hline & \multicolumn{3}{|c|}{ 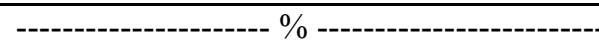 } \\
\hline Home waste disposal & 24.6 & 46.1 & 60.2 \\
\hline Pesticide/fertilizer use & 15.5 & 31.0 & 46.4 \\
\hline Motor oil disposal & 20.4 & 29.1 & 65.3 \\
\hline No actions taken & 45.6 & 26.2 & 18.6 \\
\hline
\end{tabular}

Table 3: $\quad$ Statistical significance of time (date) on voluntary actions taken by Pacific Northwest residents comparing 2002 vs. 2012 and 2007 vs. 2012.

\begin{tabular}{|c|c|c|}
\hline Action & 2002 vs. 2012 & 2007 vs. 2012 \\
\hline & \multicolumn{2}{|c|}{--------------------- p value -------------------- } \\
\hline Home waste disposal & 0.0001 & 0.0001 \\
\hline Pesticide/fertilizer use & 0.0001 & 0.0001 \\
\hline Motor oil disposal & 0.0001 & 0.0001 \\
\hline No actions taken & 0.0001 & 0.0001 \\
\hline
\end{tabular}

Based on the data shown in Tables 2 and 3 the public are getting more involved in the protection of local water quality by taking voluntary actions. Examples of voluntary actions cited by survey respondents to make home waste disposal less harmful to the environment include: (1) eliminating sink disposal of products containing metals, (2) saving products considered hazardous wastes for specific local collection days instead of throwing out with the regular trash, (3) safe disposal of unused pharmaceutical products, (4) composting food wastes when possible, (5) more frequent pump outs of septic tanks, (6) increased recycling, and (7) buying more items with minimal packaging. 
Examples of voluntary actions the public used with pesticides and fertilizers included: (1) reduced use of pesticides in yards, (2) reduced use of fertilizers in yards, (3) use of slow release fertilizers on lawns, (4) more effective timing of fertilizer applications to match nutrient availability with grass growth, (5) adhering to pesticide application rate labels on products purchased from home and garden centers, (6) making sure that target pests are present on plants prior to pesticide applications, and (7) the use of natural pesticides such as soaps which are less harmful to water quality. It is interesting that all of the above practices would be deemed best management practices (BMPs) and have been taught through many University outreach programs including the Master Gardeners Program, which is targeted at homeowners.

The rate of motor oil recycling/proper disposal appears to have more than doubled since 2007; however, a large percentage of the public has just probably realized (in the last five years) that when they pay for an oil change for their car they also pay an oil disposal fee. It is likely that at least $80 \%$ of the region's residents don't change their own oil. Consequently, the used motor oil has been recycled or safely disposed of by state law for well over a decade. So, even though this recycling is regulated, the consumer has voluntarily made the choice to have their oil changed as a paid service.

The demographic factors of state of residence, occupation, education level, and length of residence in the region did not influence the implementation of voluntary actions to protect water quality; however, gender, age and community size did significantly affect the use of voluntary activities. Although the data is not shown in tabular form gender was statistically significant. Females were more likely than males to voluntarily protect water quality through better home waste disposal methods ( 68.4 vs. $54.1 \%$ ), more effective fertilizer/pesticide use (52.8 vs. $41.7 \%$ ) and correctly disposing of used motor oil (77.4 vs. 51.9\%). Males were significantly more likely to not have taken actions to protect water quality (22.4 vs. $14.2 \%)$.

Respondent age had a significant effect on implementing voluntary actions to protect water quality by improving home waste disposal $(p=0.006)$, pesticide/fertilizer use $(\mathrm{p}=0.0001)$, and motor oil recycling/disposal $(\mathrm{p}=0.0008)$ (Table 4). It was interesting that respondents in the 30 to 50 and 50 to 70 age

Table 4: Interaction of respondent age on voluntary actions taken to protect water quality based on responses to the 2012 survey.

\begin{tabular}{|c|c|c|c|c|}
\hline \multirow{2}{*}{ Action } & \multicolumn{4}{|c|}{------------------------------Age-------------------------------. } \\
\hline & $<30$ & 30 to 50 & 50 to 70 & $>70$ \\
\hline & \multicolumn{4}{|c|}{ - - } \\
\hline Home waste disposal & 54.6 & 70.3 & 72.4 & 40.6 \\
\hline Pesticide/fertilizer use & 40.6 & 66.2 & 64.1 & 16.6 \\
\hline Motor oil disposal & 52.5 & 81.4 & 76.5 & 40.5 \\
\hline No actions taken & 19.5 & 14.2 & 16.2 & 27.5 \\
\hline
\end{tabular}


groups were most likely to implement practices to protect water quality. Respondents over the age of 70 were significantly less likely to consider water quality in their household activities. The under 30 age group did not appear to be as environmentally oriented as their 30 to 50 and 50 to 70 age counter parts; however, many wrote individual comments that they did not have to change the way they did things because environmental education in schools had taught them to consider the environment, especially water, in the first place - so they did not need to take corrective actions. Over $80 \%$ of the respondents in the $<30,30$ to 50 and 50 to 70 age groups do at least one voluntary action to protect water quality.

Community size also had a significant effect on voluntary actions taken to protect water quality (Table 5). In general, respondents living in larger communities were more likely to use water quality friendly tactics when considering home waste disposal $(p=0.0001)$, pesticide/fertilizer use $(p=0.0001)$, and motor oil disposal/recycling $(\mathrm{p}=0.0001)$. People living in larger cities and towns generally have smaller residential lots and consequently less space to dispose of wastes. In addition, urban centers in the Pacific Northwest are known for their recycling and green ethics. Both ethics probably translate into more concern and activism for the environment. It is also interesting to note that less than $11 \%$ of residents in towns of more than 100,000 people took no voluntary actions to protect water quality while this number was over $26 \%$ in towns of less than 3,500 people.

Table 5: Interaction of the community size of the respondent on voluntary actions taken to protect water quality based on responses to the 2012 survey.

\begin{tabular}{|c|c|c|c|c|c|}
\hline \multirow[t]{2}{*}{ Action } & \multicolumn{5}{|c|}{----------------Community size (in 000)------------------ } \\
\hline & $>100$ & $25-100$ & $7-25$ & $3.5-7$ & $<3.5$ \\
\hline & \multicolumn{5}{|c|}{ 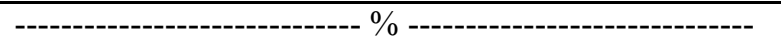 } \\
\hline Home waste disposal & 70.2 & 66.2 & 58.4 & 50.4 & 42.1 \\
\hline Pesticide/fertilizer use & 57.5 & 51.2 & 41.4 & 34.6 & 30.4 \\
\hline Motor oil disposal & 70.2 & 63.2 & 58.8 & 56.2 & 56.0 \\
\hline No actions taken & 10.6 & 18.2 & 21.6 & 23.4 & 26.5 \\
\hline
\end{tabular}

\subsection{Voluntary actions to protect water quantity}

Over $87 \%$ of survey respondents undertook at least one voluntary action to protect the quantity of water resources in the Pacific Northwest based on the 2012 survey. Voluntary actions including installation of water saving appliances, changing water use in the yard, changing household water use and changing the way a vehicle was washed were taken by $70.2,49.2,64.3$ and $32.1 \%$ of the survey respondents, respectively (Table 6). All actions were statistically more frequent when compared to the 2002 survey (Table 7). The 2012 results for installing a water-saving appliance and changing household water use were statistically more frequent than the 2007 survey results (Table 7). 
Respondent cited examples of installing water saving appliances included: (1) low flush toilets, (2) low flow shower heads, (3) fixing faucet leaks, (4) buying water efficient washing machines, (5) buying water efficient dishwashers, and (6) installing ice makers in freezers.

Table 6: Percentage of survey respondents who have taken a voluntary action to protect water quantity based on responses to the 2002, 2007 and 2012 surveys.

\begin{tabular}{|c|c|c|c|}
\hline Action & 2002 & 2007 & 2012 \\
\hline \multicolumn{4}{|c|}{ - } \\
\hline Installed water saving appliance & 40.6 & 58.8 & 70.2 \\
\hline Changed yard watering & 28.9 & 46.0 & 49.2 \\
\hline Changed household water use & 32.4 & 42.9 & 64.3 \\
\hline Changed vehicle washing & 26.7 & 30.0 & 32.1 \\
\hline No actions taken & 28.9 & 17.5 & 12.4 \\
\hline
\end{tabular}

Table 7: $\quad$ Statistical significance of time (date) on voluntary actions to protect water quantity taken by Pacific Northwest residents comparing 2002 vs. 2012 and 2007 vs. 2012.

\begin{tabular}{lcc}
\hline Action & 2002 vs. 2012 & 2007 vs. 2012 \\
\hline & 0.0001 & 0.0008 \\
Installed water saving appliance & 0.0001 & $0.072(\mathrm{NS})$ \\
Changed yard watering & 0.0001 & 0.0001 \\
Changed household water use & 0.0140 & $0.085(\mathrm{NS})$ \\
Changed vehicle washing & 0.0001 & 0.042 \\
No actions taken &
\end{tabular}

Changing yard watering strategies cited by survey respondents included: (1) watering lawns less frequently, (2) installing sprinklers, (3) installing timers on sprinkler systems, (4) watering large plants with drip irrigation, (5) using xeriscaping more often, (6) using more native plants in the landscape, (7) using grass varieties that are more tolerant of dry conditions, (8) removing portions of the lawn, and (9) replacing lawns with artificial turf.

Survey respondents indicated that they reduced home water use by doing at least one of the following: (1) taking shorter showers, (2) installing low flow shower heads, (3) using low flush toilets, (4) only wash full loads of laundry, (5) only wash full loads in the dishwasher, and (6) reduce water flowing out of the faucet when doing simple things like brushing teeth, shaving, or washing vegetables.

Getting over $60 \%$ of the public to voluntarily install a water saving device and change household water use indicated that public education about the need for wisely using water resources has been successful. Change in yard water use between 2007 and 2012 was not significant perhaps due to two factors. First, people that had control of watering yards had already made the change by 2007 
(46.0\%), and (2) renters and apartment dwellers may not have been in the position to impact yard watering. The lack of change in car washing between 2007 and 2012 may also be due to the observation that people who could make changes had already done this by 2007 (30.0\%). In addition many people take their cars to pay wash stations rather than wash vehicles at home. It appears that public education has made Pacific Northwest residents willing to try to do the right thing by taking voluntary actions to protect their water quantity resources.

The demographic factors of education and length of time living in the Pacific Northwest did not affect voluntary actions to reduce water use by survey respondents; however, gender, community size, age, and state of residence did impact actions to protect water quantity (Tables 8, 9 and 10).

Table 8: Interaction of respondent age on voluntary actions taken to protect water quantity based on responses to the 2012 survey.

\begin{tabular}{|c|c|c|c|c|}
\hline \multirow[t]{2}{*}{ Action } & \multicolumn{4}{|c|}{-----------------------------Age------------------------------- } \\
\hline & $<40$ & 40 to 50 & 50 to 70 & $>70$ \\
\hline \multicolumn{5}{|c|}{ 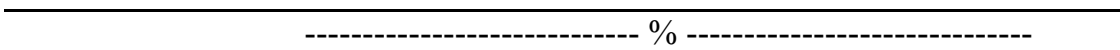 } \\
\hline Water saving appliance & 60.3 & 80.1 & 78.6 & 50.1 \\
\hline Changed yard watering & 39.4 & 62.4 & 52.5 & 38.6 \\
\hline Changed household water use & 59.4 & 70.1 & 64.0 & 54.4 \\
\hline No actions taken & 9.4 & 8.4 & 10.2 & 16.9 \\
\hline
\end{tabular}

Table 9: Interaction of respondent state of residence on voluntary actions taken to protect water quantity based on responses to the 2012 survey.

\begin{tabular}{|c|c|c|c|c|}
\hline \multirow[t]{2}{*}{ Action } & \multicolumn{4}{|c|}{ 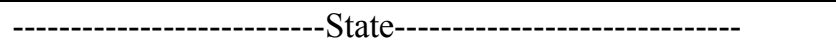 } \\
\hline & AK & ID & OR & WA \\
\hline \multicolumn{5}{|c|}{ 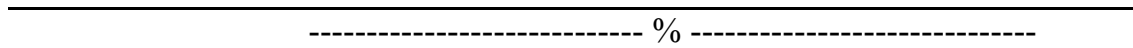 } \\
\hline Water saving appliance & 49.6 & 63.2 & 76.7 & 75.4 \\
\hline Changed yard watering & 30.6 & 56.4 & 49.6 & 51.1 \\
\hline Changed household water use & 55.8 & 67.3 & 64.1 & 65.4 \\
\hline No actions taken & 20.4 & 9.4 & 9.0 & 9.6 \\
\hline
\end{tabular}

Table 10: Interaction of the community size of the respondent on voluntary actions taken to protect water quantity based on responses to the 2012 survey.

\begin{tabular}{|c|c|c|c|c|c|}
\hline \multirow[t]{2}{*}{ Action } & \multicolumn{5}{|c|}{ 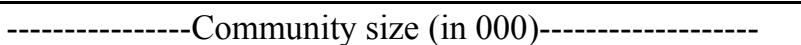 } \\
\hline & $>100$ & $25-100$ & $7-25$ & $3.5-7$ & $<3.5$ \\
\hline & \multicolumn{5}{|c|}{ 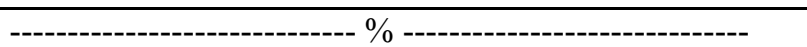 } \\
\hline Water saving appliance & 80.4 & 72.6 & 66.0 & 59.0 & 59.5 \\
\hline Household water use & 70.6 & 66.4 & 63.1 & 60.8 & 58.6 \\
\hline No actions taken & 5.3 & 10.1 & 15.2 & 17.3 & 19.4 \\
\hline
\end{tabular}


Although not shown in tabular form, based on the 2012 survey females were more likely than males to have installed a water saving appliance (76.2 vs. $65.1 \% ; p=0.02)$, changed watering in the yard (57.8 vs. $41.4 \% ; p=0.004)$, changed household water use $(67.6$ vs. $60.5 \% ; \mathrm{p}=0.03)$, and changed how a vehicle was washed (37.9 vs. $26.4 \%$; $=0.026)$. Gender produced similar significant statistical trends for both water quality and water quantity actions assessed in the survey.

Respondent age had a significant impact on the voluntary actions of installing a water saving appliance $(p=0.004)$, changing water use in the yard $(p=0.0006)$, and changing household water use $(\mathrm{p}=0.008)$ in the 2012 survey (Table 8). Age did not impact voluntary actions to change the way a vehicle was washed. Less than $11 \%$ of the survey respondents in the less than 40,40 to 50 , and 50 to 70 age groups took no actions to voluntarily protect water (quantity) resources (Table 8 ). However, a much higher $16.9 \%$ of respondents older than 70 did not take one or more proactive water quantity actions $(\mathrm{p}=0.0001)$.

State of residence impacted answers to installing a water saving appliance $(\mathrm{p}=0.003)$, changing water use in the yard $(\mathrm{p}=0.004)$, and changing household water use $(\mathrm{p}=0.03)$ (Table 9). The responses from Alaska were the most likely reason for the observed significant differences. Alaska residents were less likely to voluntarily take the three significant actions compared to residents of Idaho, Oregon and Washington. Oregon and Washington residents responded similarly to all three actions. Idaho residents were less likely to install water savings appliances but more likely to change yard watering compared to Oregon and Washington.

Differences between states can likely be related to climatic factors. First, there is very little perception of water shortages in larger sized cities and towns in Alaska. Second, the highly populated areas of Washington and Oregon receive adequate annual precipitation to meet most needs; however, the high and rapidly increasing population tends to offset the water surplus. Third, Idaho is the driest state and thus the tendencies for changes in yard and household water use is apparent. Over $90 \%$ of Idaho, Oregon and Washington survey respondents have taken at least one action to protect water (quantity) resources, while one in five Alaska residents have taken no actions $(\mathrm{p}=0.0001)$ (Table 9).

Community size significantly impacted the rate of voluntary actions to install water saving appliances $(p=0.024)$ and change household water use $(p=0.013)$ (Table 10). Community size did not impact change in yard water use and change in washing a vehicle. In general, respondents living in larger cities and towns were more likely to have installed a water savings appliance than counterparts in smaller communities (Table 10). The same significant trend is also seen for changes in household water use. Community size affected answers to both water quality and water quantity actions in a similar fashion. Over $94 \%$ of survey respondents in communities with more than 100,000 took at least one voluntary action to address water (quantity) resources. In contrast almost $20 \%$ of respondents in communities with less than 7,000 people took no actions to address the same issues. 


\section{Conclusions and recommendations}

Successful public education projects have resulted in the implementation of effective voluntary actions to protect water resources. The outreach arm of land grant universities has successfully led community-based educational efforts that are now at least in part protecting the region's water resources. This university outreach arm called Extension (sometimes Cooperative Extension, Cooperative Extension Service, or Cooperative Extension System) effectively operates at the local, state and national levels. The high levels of voluntary actions shown in the regional survey data suggest that voluntary educational efforts can be at least as effective as regulatory efforts from both an implementation and cost effectiveness standpoint.

More than $87 \%$ of the region's adults have made lifestyle changes to address water quantity issues. For instance, $70 \%$ have installed at least one water-saving appliance in their home, $49 \%$ report that they have reduced water use in their yards, $64 \%$ have reduced water use in their home, and $32 \%$ have reduced the amount of water used washing their cars. Conversely, only $13 \%$ have not made voluntary changes to address the amount of water used. Almost $82 \%$ of adults have acted to improve water quality. Voluntary water quality actions taken include: changed the disposal of household wastes $(60 \%)$, reduced the use of fertilizers and pesticides in yards (46\%), and changed the disposal of used motor oil (65\%). Less than $19 \%$ of adults have not voluntarily addressed water quality issues in their homes. This study demonstrates that education to cause positive voluntary actions is very effective and may work better than the regulatory approach in this region of the USA.

People in the Pacific Northwest have made voluntary changes in the way they deal with water on a daily basis. These changes are probably rooted in two things. First, residents of this region place a high value on their water resources and they know that these resources are limited. Second, many of the voluntary actions taken by the public not only have positive environmental consequences, but in the short and middle terms these actions may result in economic benefits. These potential economic benefits may result in a lowering or simply maintaining current costs of water services and wastewater treatment.

The data presented in this paper should make politicians in the USA take notice that adult education about water resource issues does work. In fact adult education when it works is almost always less expensive than regulatory actions and in the case of the data presented in this paper is far more cost effective.

\section{Acknowledgement}

The authors would like to acknowledge USDA-NIFA for supporting this survey work over the last 12 years as a portion of the Pacific Northwest Water Resources Coordination Project. 


\section{References}

[1] Anonymous, Voluntary action needed to protect water quality, Journal of Environmental Health, 53:6, 1990.

[2] May, P.J., Marine facilities and water quality: Regulatory versus voluntary approaches, Coastal Management, 31:297-317, 2003.

[3] Neufield, D.A., An ecosystem approach for groundwater: The case of Waterloo Region, Ontario, Canada, Hydrogeology Journal, 8:239-250, 2000.

[4] Pumphrey, R.G., Edwards, J.A., and Becker, K.G., Urban and rural attitudes toward municipal water controls: A study of a semi-arid region with limited water supplies, Ecological Economics, 65:1-12, 2008.

[5] Koski, C. and May, P.J., Interest and implementation: Fostering voluntary regulatory actions, Journal of Public Administration Research and Theory, 16:329-349, 2006.

[6] Mahler, R.L., Simmons, R., and Simmons, F., Public perceptions and actions toward sustainable groundwater management in the Pacific Northwest region, USA, International Journal of Water Resources Development, 21:465-472, 2005.

[7] Shepard, R., Evaluating extension-based water resource outreach programs: Are we meeting the challenge? Journal of Extension, [On-line], 40(1). Available at: http://www.joe.org/joe/2002february/a3.html, 2002.

[8] Mahler, R. L., Simmons, R., Sorensen, F., and Miner, J.R., Priority water issues in the Pacific Northwest, Journal of Extension, [On-line], 42(5). Article 5RIB3. Available at: http://www.joe.org/joe/2004october/rb3.php, 2004.

[9] Salent, P., and Dillman, D., How to Conduct Your own Survey. John Wiley and Sons, Inc. New York, New York, 1994.

[10] Dillman, D., Mail and Internet Surveys: The Tailored Design Method. John Wiley and Sons, Inc. New York, New York, 2000.

[11] Mahler, R. L., Simmons, R., Sorensen, F., and Miner, J.R., Priority water issues in the Pacific Northwest, Journal of Extension [On-line], 42(5). Article 5RIB3. Available at: http://www.joe.org/joe/2004october/rb3.php, 2004.

[12] Mahler, R.L., Gamroth, M., Pearson, P., Sorenson, F., Barber, M.E. and Simmons, R., Information sources, learning opportunities and priority water issues in the Pacific Northwest, Journal of Extension [On-line], 48(2). Article 2RIB2. Available at: http://www.joe.org/joe/2010april/rb2.php, 2010.

[13] SAS Institute Inc., SAS Online Document 9.1.3. Cary, North Carolina: SAS Institute Inc., 2004.

[14] Babbie, E., The practice of social research. 3rd edition. Wadsworth Publishing Company. Belmont, CA. pp. 359, 424, 1983. 